\title{
Electrical Percent Loading Assessment for the Distribution Transformers Residential-Used of a Barangay
}

\author{
Romalyn H. Gomez, John Leslie M. Dizon, Christine Ann S. Teodoro, \\ Joeme Carl Demegillo, Noel T. Florencondia
}

\begin{abstract}
Proper rating of transformer is important to maximize the useful life and efficiency of the equipment. A higher or lower rating of the transformer can provide either a higher system loss or disconnection of consumer to an electricity provider. In this study, assessment of residential transformer of a barangay was considered. The percent loading of each transformers was evaluated by the used of the standard set by National Electrification Administration (NEA). The software used in the study is Microsoft Excel 2016 for determining the percent loading of each residential transformers. After the percent loading was identified, clustering of transformers was made according to the loading conditions. Changes in rating were also performed to correct the percent loading of the transformer. From 2017 to 2019, 13 transformers or $48.14 \%$ were underloaded while 6 or $22.22 \%$ were found to be overloaded. By changing the rating of the transformer in the barangay, the percent loading of the 6 overload transformers were corrected. For the 13 underloads, 12 of which were amended. Moreover, there is still an underload unit RT19 considering the change in rating the available lowest rating of the transformer was already reached. The researchers recommend using load centering to minimize the number of transformers. To compare the monthly $\mathrm{kWhr}$ consumption, the monitor of the daily basis $k W H r$ ingestion using Automated Mapping/Facility Management/ Geographical Information System or AM/FM/GIS was endorsed to identify the peak load of each transformer.
\end{abstract}

Keywords: kVA Rating, Residential Transformers, Overload, Underload

\section{INTRODUCTION}

Distribution system is a process by which electricity is transformed for the utilization of consumers. One equipment used for this process is transformer. Distribution Transformers were classified into two:

a. Sole Used Distribution Transformer where only one consumer is connected

Revised Manuscript Received on February 05, 2020

* Correspondence Author

Romalyn H. Gomez. Instructor, Electronics and Communications Engineering Department, Don Honorio Ventura State University (DHVSU), Philippines.

John Leslie M. Dizon. Staff Engineer , Technical Services Department , Pampanga I Electric Cooperative (PELCO I), Philippines.

Christine Ann S. Teodoro. College Instructor, Electrical Engineering Department, Technological Institute of the Philippines - Quezon City (TIP-QC), Philippines.

Joeme Carl Demegillo. Production Manager, D'Truck Specialist Inc.

Noel T. Florencondia. Dean, College of Engineering of Nueva Ecija University of Science and Technology (NEUST), Philippines.

C The Authors. Published by Blue Eyes Intelligence Engineering and Sciences Publication (BEIESP). This is an open access article under the CC BY-NC-ND license (http://creativecommons.org/licenses/by-nc-nd/4.0/) b. Commonly Used or Residential Distribution Transformer where multiple consumers are connected

Distribution transformer loading for consumers' connectivity plays an essential role at present. Appropriate rating of transformer is imperative for proper utilization. Failure of transformer may cause power interruption and oversizing of which may result to higher losses [1].

Rapid growth of economic development in some areas may result to the overloading of distribution transformer and some were underloaded due to the availability of the equipment. It is a must to give attention to the utility for proper operation [2]. Some of the common problems occur in the transformer were: unbalanced loading and usage of repaired distribution transformer [3]. For a distribution transformer to fully utilized, it needs $40 \%$ to $70 \%$ loading conditions and to achieve the maximum efficiency, it should be approximately $50 \%$ of its rated rating [4].

Quantifying the connected loads in each distribution transformer is significant. Knowing the number of consumers using the transformer for its loading condition is vital for continuous connectivity. Proper rating for the demand of electrical energy can help the transformer to maximize its utilization and useful life [5].

Transformer loading can be classified into three conditions:

1. Underload - below $40 \%$ percent loading

2. Normal $-40 \%$ to $70 \%$ percent loading

3. Overload - higher than $70 \%$ loading

To avoid underloading and overloading a transformer, proper loading conditions and the adaptation on the increasing demand of energy must be taken for considerations [6-7].

Pampanga, subdivided to 3 cities and 19 municipalities, is one of the provinces in Central Luzon Region in the Philippines. One of the municipalities of Pampanga is Arayat which has 30 barangays.

This municipality was served by an Electric Utility with 3 distribution feeders namely Feeder number 1,2, and 3 . As seen in Figure 1, the number of residential consumers of the 3 feeders were 8116,5256 , and 6515 , respectively.

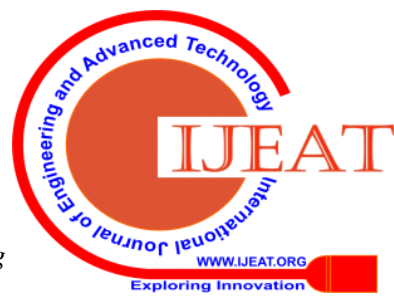




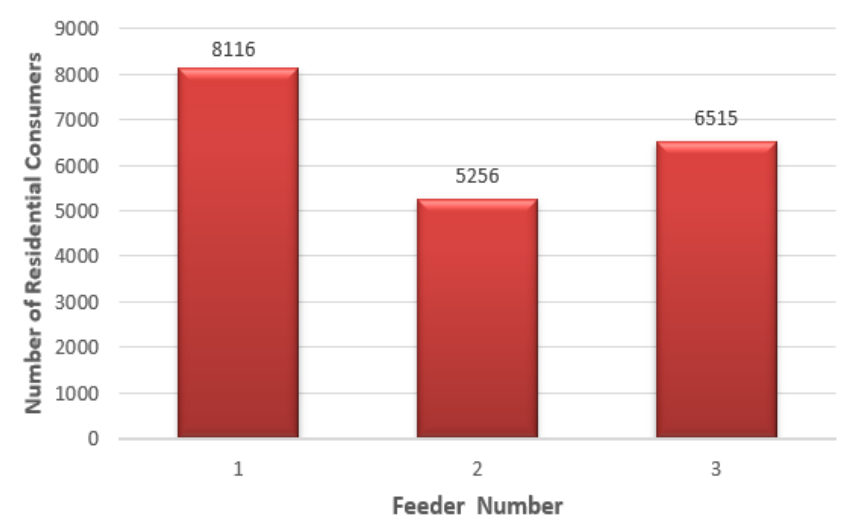

Figure 1: Number of Residential Consumers per Feeder

Furthermore, these residential consumers were connected to a distribution transformer for electricity utilization. Figure 2 shows the number of residential distribution transformer per feeder.

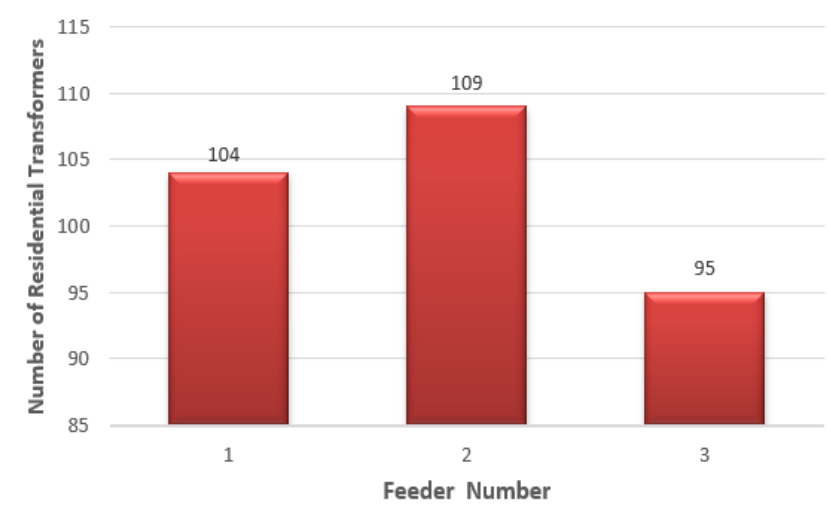

Figure 2: Number of Residential Transformers per Feeder

From the three feeders, Feeder 1 has the highest number of residential consumers and ranked second on the number of residential transformers. The $\mathrm{kWh}$ demand of feeder 1 from 2017 to 2019 was shown in figure 3.

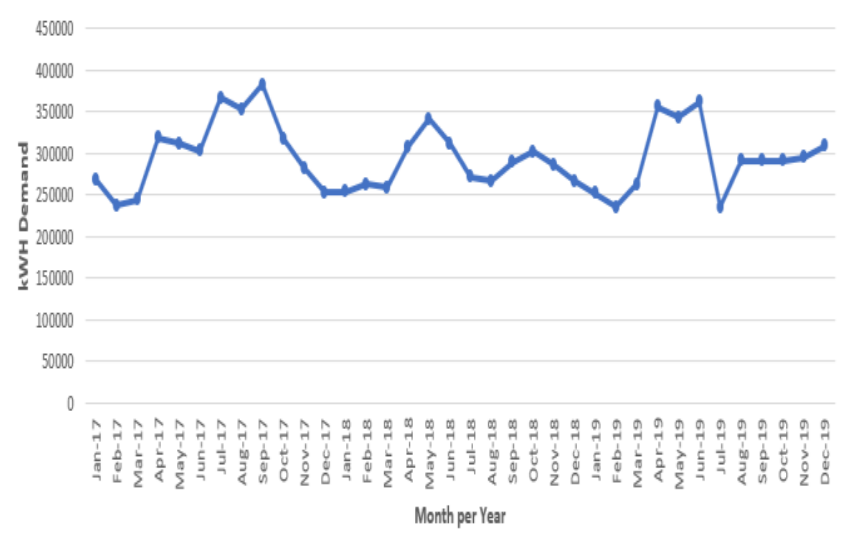

Figure 3: kWh of Feeder 1

For the past 3 years there is an increasing trend of demand in the feeder and it was experienced under the month of April, May and June. Feeder 1 assists the barangays of Cacutud (0414), Matamo (0413), Plazang Luma West (0412), Plazang Luma East (0411), San Agustin Sur (0409), Paralaya (0408), Guemasan (0407), Riverside (0406), Poblacion (0405) , Manga (0404), Cupang (0403), San Jose Mesulo (0402) and San Nicolas (0401). Figure 4 represents the number of consumers per barangay. Likewise, the subdivision of the 104-residential transformer per barangay were shown in Figure 5.

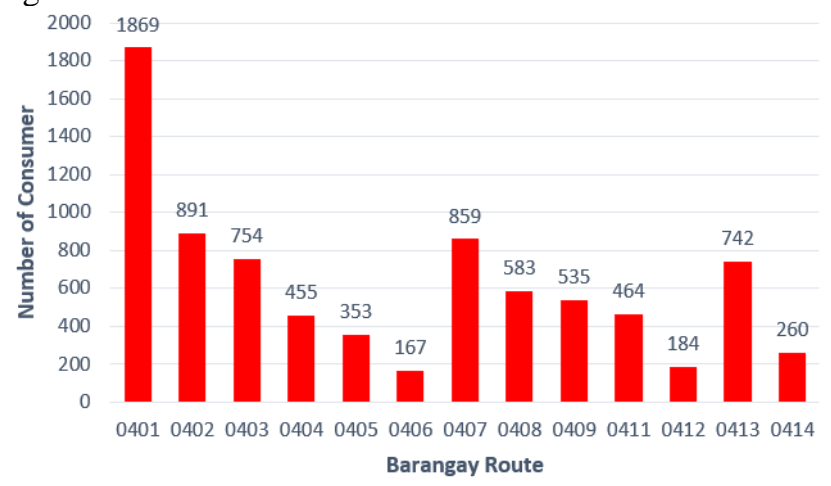

Figure 4: Number of Consumer per Barangay

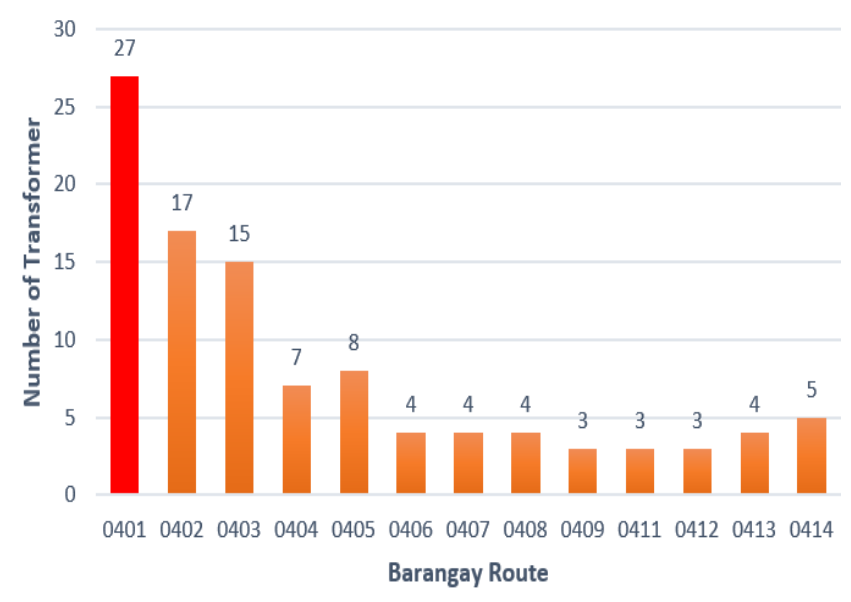

Figure 4: Number of Transformer per Barangay

As shown, barangay San Nicolas has the most residential consumer and transformers. In lieu, this barangay has been chosen to be evaluated regarding the percent loading condition of the residential transformers herein.

The objective of the study is to assess the loading conditions of residential consumers of a barangay. Similarly, to categorized residential transformer into overload, normal load and underload settings. Also, changes on ratings should be imposed, such as upgrading and downgrading, to the overload and underload transformer.

This study will give an aid in monitoring the loadings of residential transformers. Correspondingly, it can be helpful in maximizing the utilization of the equipment used. It can also provide information on the present situation of the residential transformers.

The study will cover the 27 residential transformers and 1869 consumers of Barangay San Nicolas. The percent loading condition of underload or below $40 \%$ loading, normal load or $40 \%$ - $70 \%$ loading, overload or higher $70 \%$ will be applied [4], considering the residential power factor of 0.85 [6]. Uprating and downrating will also be considered in the study.

Published By:

Blue Eyes Intelligence Engineering DOI: 10.35940/ijeat.C5920.029320 


\section{METHODOLOGY}

\section{A. Data Collection and Instrument}

$\mathrm{kVA}$ rating of each residential transformer as well as the energy consumption in $\mathrm{kWh}$ per consumer connected in each transformer were collected through the electric utility. These data will be used to assess the percent loading conditions of the residential transformers. The conceptual framework of the study is shown in figure 6.

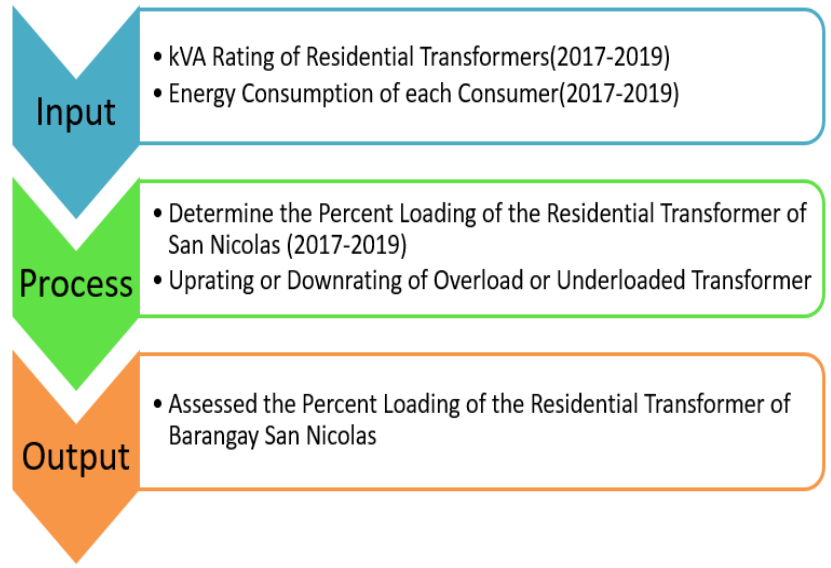

Figure 6: Conceptual Framework of the Study

\section{B. Data Analysis for the Percent Loading} conditions of the residential transformer of barangay San Nicolas including the energy consumption (January 2017 December 2019) of consumer connected using Microsoft Excel 2016 applying the standard formula set by National Electrification Administration (NEA) System Loss Reduction Manual [8].

$$
\% \text { Loading }=\frac{\text { kWhrDemand }(\text { month })}{\left(\mathrm{KVA}_{\mathrm{TR}}\right)(\mathrm{PF})(720 \mathrm{H})}
$$

When the percent loading was identified, residential transformers will be classified into three loading conditions:

1. Underload - below $40 \%$ percent loading

2. Normal $-40 \%$ to $70 \%$ percent loading

3. Overload - higher than $70 \%$ loading

\section{Changing of Rating of Transformer}

Upon determining the transformers loading condition, the change into a higher rating of kVA should be done for the overload transformers and replace a lower rating one for the underload transformers for the percent loading to become normal. The rating of the transformer used by the electric utility are $10 \mathrm{kVA}, 15 \mathrm{kVA}, 25 \mathrm{kVA}, 37.5 \mathrm{kVA}, 50 \mathrm{kVA}$, $75 \mathrm{kVA}$ and $100 \mathrm{kVA}$.

\section{RESULTS \& DISCUSION}

\section{A. Transformer Assessment}

The graphical representation of the number of underloads, normal load and overload residential transformer are shown in Figures 7-9 respectively. In Figure 7, the number of underload transformers gradually decreases due to the increase of demand in electric usage under the months of March, April and May while on the months of November to January, it slowly increases due to the less demand during
Data gathered will be used to identify the loading

cold weather. There are 19 maximum number of underload transformers occurred in December 2017.

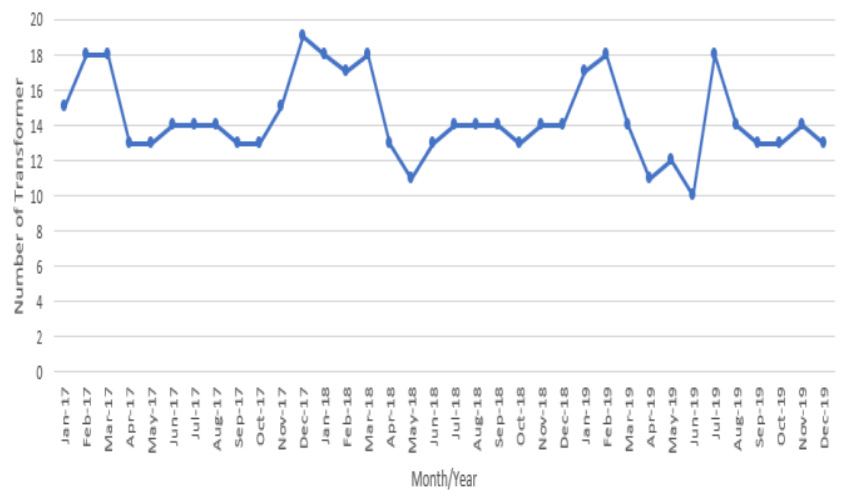

Figure 7: Number of Underload Transformers

Figure 8 shows that in April and June 2019, there are only a maximum of 7 normal load out of 27 transformers installed in the barangay.

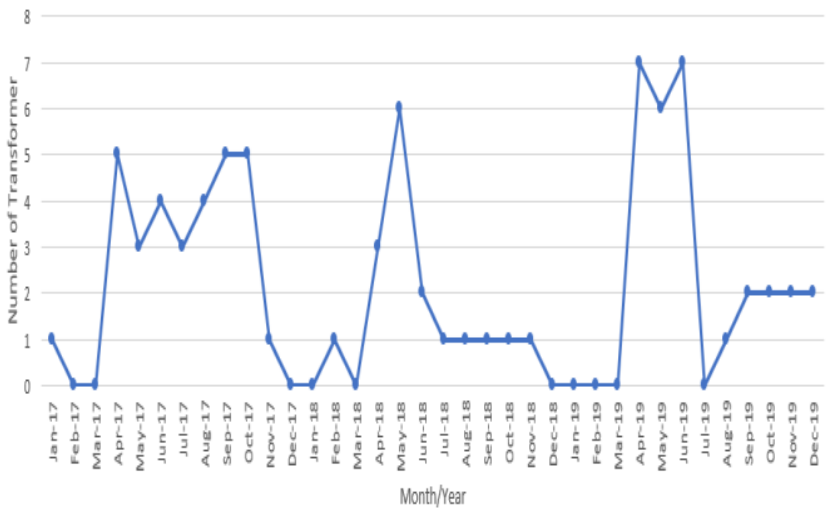

Figure 8: Number of Normal Load Transformers

Figure 9 illustrates that there are 13 overload transformers in maximum from 2017-2019.

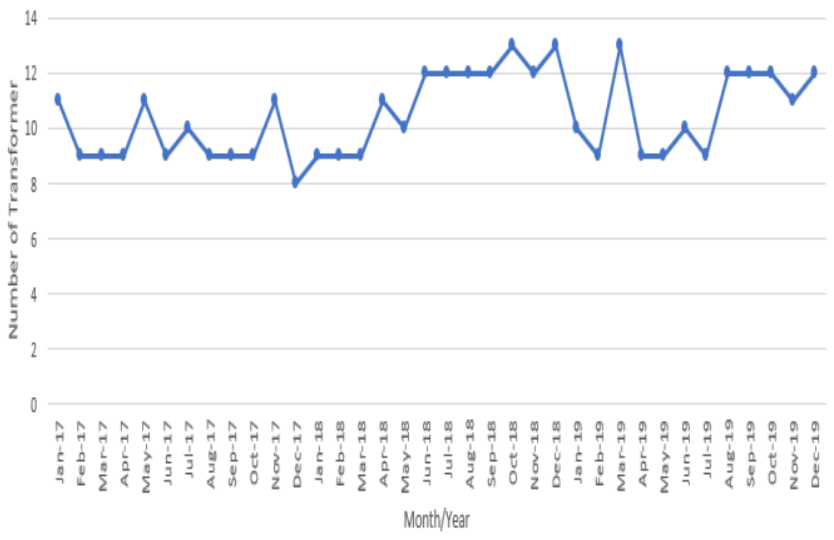

Figure 9: Number of Overload Transformers

The average performance of each transformer condition was shown in Figure 10. From 2017-2019, there are 8 overload transformers, 13 underloads and 6 in normal load. 


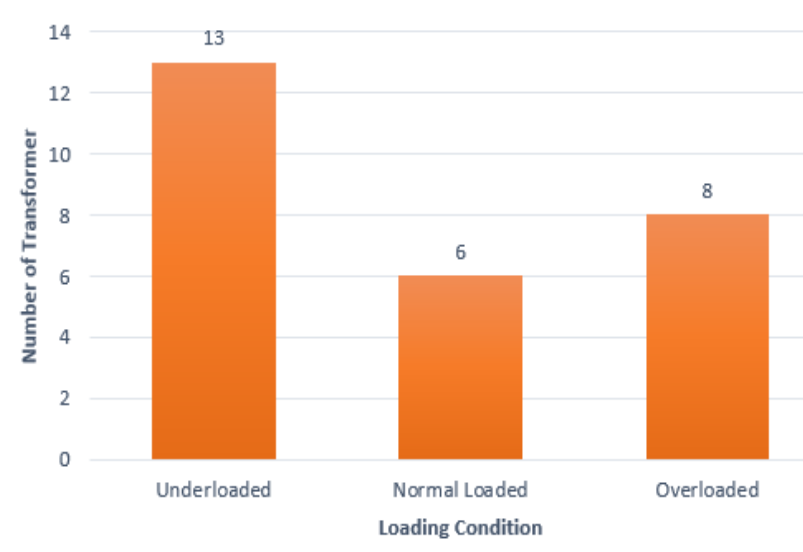

Figure 10: Loading Conditions of Residential Transformers (2017-2019)

\section{B. Changing of Rating of Transformer}

\section{B.1. Underload Residential Transformer}

In Table 1, residential transformers in underload condition were presented. Additionally, the old rating of the transformer and percent loading were changed into a lower rating with a percent loading under normal loading conditions which is between $40 \%$ to $70 \%$.

Table 1: Underload Residential Transformer

\begin{tabular}{|r|l|l|l|l|l|}
\hline No & $\begin{array}{l}\text { Transformer } \\
\text { Name }\end{array}$ & $\begin{array}{l}\text { Old } \\
\text { Rating } \\
\text { kVA) }\end{array}$ & $\begin{array}{l}\text { New } \\
\text { Rating } \\
\text { (kVA) }\end{array}$ & $\begin{array}{l}\text { Old } \\
\text { Percent } \\
\text { Loading }\end{array}$ & $\begin{array}{l}\text { New } \\
\text { Percent } \\
\text { Loading }\end{array}$ \\
\hline 1 & RT01 & 37.5 & $\mathbf{1 5}$ & 18.84 & $\mathbf{4 7 . 0 9}$ \\
\hline 2 & RT03 & 75 & $\mathbf{1 5}$ & 12.34 & $\mathbf{6 1 . 7 0}$ \\
\hline 3 & RT04 & 75 & $\mathbf{2 5}$ & 14.65 & $\mathbf{4 3 . 9 5}$ \\
\hline 4 & RT05 & 75 & $\mathbf{3 7 . 5}$ & 22.36 & $\mathbf{4 4 . 7 1}$ \\
\hline 5 & RT06 & 75 & $\mathbf{1 5}$ & 8.66 & $\mathbf{4 3 . 3 2}$ \\
\hline 6 & RT07 & 75 & $\mathbf{3 7 . 5}$ & 29.32 & $\mathbf{5 8 . 6 4}$ \\
\hline 7 & RT11 & 37.5 & $\mathbf{2 5}$ & 38.09 & $\mathbf{5 7 . 1 4}$ \\
\hline 8 & RT14 & 25 & $\mathbf{1 5}$ & 26.79 & $\mathbf{4 4 . 6 6}$ \\
\hline 9 & RT16 & 25 & $\mathbf{1 0}$ & 24.02 & $\mathbf{6 0 . 0 6}$ \\
\hline 10 & RT19 & 25 & $\mathbf{1 0}$ & 4.17 & $\mathbf{1 0 . 4 4}$ \\
\hline 11 & RT21 & 50 & $\mathbf{3 7 . 5}$ & 36.76 & $\mathbf{4 9 . 0 1}$ \\
\hline 12 & RT22 & 50 & $\mathbf{3 7 . 5}$ & 39.41 & $\mathbf{5 2 . 5 5}$ \\
\hline 13 & RT23 & 25 & $\mathbf{1 0}$ & 23.59 & $\mathbf{5 8 . 9 7}$ \\
\hline
\end{tabular}

Among the 13 underload transformers, one is still in the underload condition. RT19 initially $25 \mathrm{kVA}$ was installed and a percent loading of 4.17 was applied. The rating was corrected into $10 \mathrm{kVA}$ with a new percent loading of 10.44 . With these, it's still cannot be adjusted due to the lowest value of the 10-kVA rating.

B.2. Overloaded Residential Transformer

The current rating and present percent loading of the transformers in the overload condition are shown in Table 2. In the same way, the corrected rating and percent loading were presented.

Table 2: Overloaded Residential Transformer

\begin{tabular}{|r|l|l|l|l|l|}
\hline No & $\begin{array}{l}\text { Transformer } \\
\text { Name }\end{array}$ & $\begin{array}{l}\text { Old } \\
\text { Rating } \\
\text { (kVA) }\end{array}$ & $\begin{array}{l}\text { New Rating } \\
\text { (kVA) }\end{array}$ & $\begin{array}{l}\text { Old } \\
\text { Percent } \\
\text { Loading }\end{array}$ & $\begin{array}{l}\text { New } \\
\text { Percent } \\
\text { Loading }\end{array}$ \\
\hline 1 & RT02 & 37.5 & $\mathbf{5 0}$ & 71.13 & $\mathbf{5 1 . 1 0}$ \\
\hline 2 & RT10 & 37.5 & $\mathbf{5 0}$ & 79.45 & $\mathbf{5 9 . 5 9}$ \\
\hline 3 & RT17 & 25 & $\mathbf{3 7 . 5}$ & 72.50 & $\mathbf{4 5 . 7 4}$ \\
\hline
\end{tabular}

\begin{tabular}{|l|l|l|l|l|l|}
4 & RT18 & 15 & $\mathbf{2 5}$ & 76.66 & $\mathbf{4 5 . 9 9}$ \\
\hline 5 & RT20 & 15 & $\mathbf{2 5}$ & 95.39 & $\mathbf{5 7 . 2 4}$ \\
\hline 6 & RT24 & 25 & $\mathbf{3 7 . 5}$ & 73.50 & $\mathbf{4 6 . 3 4}$ \\
\hline 7 & RT25 & 50 & $\mathbf{7 5}$ & 74.53 & $\mathbf{4 9 . 6 9}$ \\
\hline 8 & RT26 & 50 & $\mathbf{7 5}$ & 76.27 & $\mathbf{5 0 . 8 5}$ \\
\hline
\end{tabular}

As understood, all the overload residential transformers were adjusted to a normal loading condition.

\section{CONCLUSION}

From the past 3 years, starting from 2017 to 2019, 13 residential transformers of barangay San Nicolas out of 27 or $48.15 \%$ were underload and 6 or $22.22 \%$ were found to be overloaded. Overall, 19 transformers from the 27 transformers or $70.37 \%$ must be considered.

In view of the results obtained from this study, by changing the rating of the residential transformers, all in the overload condition were finely adjusted in the normal percent loading (40 to $70 \%$ ). On the other hand, as for the underload transformers, 12 of which were corrected but there is still 1 unit, RT19, was unable to be amended due to its corrected rating being the lowest value of transformer used by the utility.

\section{V.RECOMMEDATIONS}

For future works, the researcher recommends using proper load centering to minimize the number of the transformer. For further improvement, monitoring of kWHr consumption must be done on a daily basis through the use of Automated Mapping/Facility Management/ Geographical Information System or AM/FM/GIS in identifying the peak load of each transformer to be compared to the monthly kWhr used.

\section{REFERENCES}

1. R. Singh and A. Singh, (2010). Causes of Failure of Distribution Transformer in India, 2010 9th International Conference on Environment and Electrical Engineering

2. M. Li, Q. Zhou, SMIEEE, and Z. Yang , (2015), Distribution transformer mid-term heavy load and overload pre-warning based on logistic regression, 2015 IEEE Eindhoven PowerTech

3. N. Panditl, R.L.Chakrasali, (2017), Distribution Transformer Failure in India Root Causes and Remedies, International Conference on Innovative Mechanisms for Industry Applications (ICIMIA 2017)

4. Electric Cooperative's Distribution Utility Manual (August 2009) RetrievedonSeptember11,2018,fromhttp://www.gmcdmc.ph/pdf_files _dmc /ECDU\%20Planning\%20Manual\%2010Aug2009.pdf.

5. Ali Arefi, Mahmood-reza Haghifam, Akbar Yavartalab, Javad Olamaei and Hessam Keshtar (2009), Loss Reduction Planning in Electric Distribution Networks of Iran, Retrieved on June 19, 2019fromhttp://0ieeexplore.ieee.org.lib1000.dlsu.edu.ph/stamp/stamp. jsp?tp=\&arnumber=05876386.

6. M. Teng Au, T. Anthony, N. Kamaruddin*, R. Verayiah, S. A. Mustaffa and M. Yusoff, (2008), A Simplified Approach in Estimating Technical Losses in Distribution Network Based on Load Profile and Feeder Characteristics, 2nd IEEE International Conference on Power and Energy (PECon 08), December 1-3, 2008, Johor Baharu, Malaysia

7. National Electrification Administration (NEA) and Japan International Cooperative Agency (JICA), Electric Cooperatives System Loss Reduction Manual, Identifying Countermeasures against Technical Losses for the Low Voltage System, (2013), (pp29-76).

8. National Electrification Administration, System Loss Reduction Manual, DX3430, (1993), Engineering Bulletin. National Electrification Administration (pp1-61). 


\section{AUTHORS PROFILE}

Romalyn H. Gomez. Instructor 1 under the

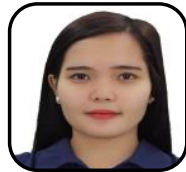

Electronics and Communications Engineering Department of Don Honorio Ventura State University (DHVSU). A licensed Electronics Engineer and Electronics Technician. Currently enrolled at Nueva Ecija University of Science and Technology (NEUST) with a degree of Master of Engineering Management (MEnM). Focuses on BMS automation and control, mobile telecommunication and project management

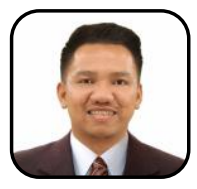

John Leslie M. Dizon. Staff Engineer under Technical Services Department of Pampanga I Electric Cooperative (PELCO I). A licensed Electrical Engineer and Master Electrician. Currently enrolled at Nueva Ecija University of Science and Technology (NEUST) with a degree of Master of Engineering Management (MEnM). He focuses in Power System Operations, Substation Maintenance and Planning and Design of Electric Distribution Lines.

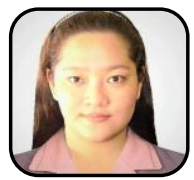

Christine Ann S. Teodoro. College Instructor under the Electrical Engineering Department of Technological Institute of the Philippines - Quezon City (TIP-QC). A licensed Electrical Engineer and Master Electrician. Currently enrolled at Nueva Ecija University of Science and Technology (NEUST) with a degree of Master of Engineering Management (MEnM). She focuses in academic-related and research-related subjects such as Illumination Engineering Design, Electrical Engineering Circuits, Research, etc.

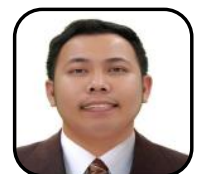

Joeme Carl Demegillo. Production Manager of D'Truck Specialist Inc. A licensed Mechanical Engineer, Master Plumber and Master Electrician. Currently enrolled at Nueva Ecija University of Science and Technology (NEUST) with a degree of Master of Engineering Management (MEnM). He focuses in Plant Production of Japanese Reconditioned Trucks.

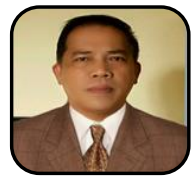

Noel T. Florencondia. Dean of the College of Engineering of Nueva Ecija University of Science and Technology (NEUST). A Professional Electrical Engineer (PEE) and Graduate of Doctor of Philosophy in Engineering Management (PhD. EnM) at Nueva Ecija University of Science and Technology (NEUST). A member of Institute on Integrated Electrical Engineers. Electrical System Design, High Rise Building Designs and Arc Flashes are his field of research. 